\title{
Health-related quality of life and long-term prognosis in chronic hypercapnic respiratory failure: a prospective survival analysis
} Stephan Budweiser*†1, Andre P Hitzl ${ }^{\dagger 1}$, Rudolf A Jörres ${ }^{2}$, Kathrin Schmidbauer ${ }^{1}$, Frank Heinemann ${ }^{1}$ and Michael Pfeifer ${ }^{1,3}$

\author{
Address: ${ }^{1}$ Center for Pneumology, Donaustauf Hospital, Donaustauf, Germany, ${ }^{2}$ Institute and Outpatient Clinic for Occupational and \\ Environmental Medicine, Ludwig-Maximilians-University, Munich, Germany and ${ }^{3}$ Department of Internal Medicine II, Division of Respirology, \\ University of Regensburg, Regensburg, Germany \\ Email: Stephan Budweiser* - stephan.budweiser@klinik.uni-regensburg.de; Andre P Hitzl - crissithedog@freenet.de; \\ Rudolf A Jörres - rudolf.joerres@med.uni-muenchen.de; Kathrin Schmidbauer - kathrin2.schmidbauer@klinik.uni-regensburg.de; \\ Frank Heinemann - frank.heinemann@klinik-donaustauf.de; Michael Pfeifer - michael.pfeifer@klinik.uni-regensburg.de \\ * Corresponding author †Equal contributors
}

Published: 17 December 2007

Respiratory Research 2007, 8:92 doi:10.1 186/1465-9921-8-92
Received: 10 October 2007

Accepted: 17 December 2007

This article is available from: http://respiratory-research.com/content/8/I/92

(C) 2007 Budweiser et al; licensee BioMed Central Ltd.

This is an Open Access article distributed under the terms of the Creative Commons Attribution License (http://creativecommons.org/licenses/by/2.0), which permits unrestricted use, distribution, and reproduction in any medium, provided the original work is properly cited.

\begin{abstract}
Background: Health-related quality of life (HRQL) is considered as an important outcome parameter in patients with chronic diseases. This study aimed to assess the role of disease-specific HRQL for long-term survival in patients of different diagnoses with chronic hypercapnic respiratory failure (CHRF).

Methods: In a cohort of 23 I stable patients (chronic obstructive pulmonary disease (COPD), $n=98$; nonCOPD (obesity-hypoventilation syndrome, restrictive disorders, neuromuscular disorders), $n=133$ ) with CHRF and current home mechanical ventilation (HMV), HRQL was assessed by the disease-specific Severe Respiratory Insufficiency (SRI) questionnaire and its prognostic value was prospectively evaluated during a follow-up of 2-4 years, using univariate and multivariate regression analysis.

Results: HRQL was more impaired in COPD (mean \pm SD SRI-summary score (SRI-SS) $52.5 \pm 15.6$ ) than non-COPD patients $(67.6 \pm 16.4 ; \mathrm{p}<0.00 \mathrm{I})$. Overall mortality during $28.9 \pm 8.8$ months of follow-up was $19.1 \%$ ( $31.6 \%$ in COPD, 9.8\% in non-COPD). To identify the overall role of SRI, we first evaluated the total study population. SRI-SS and its subdomains (except attendance symptoms and sleep), as well as body mass index (BMI), leukocyte number and spirometric indices were associated with long-term survival $(p<0.01$ each). Of these, SRI-SS, leukocytes and forced expiratory volume in I $\mathrm{s}(\mathrm{FEV}$, ) turned out to be independent predictors ( $p<0.05$ each). More specifically, in non-COPD patients SRI-SS and most of its subdomains, as well as leukocyte number, were related to survival $(p<0.05)$, whereas in patients with COPD only BMI and lung function but not SRI were predictive.

Conclusion: In patients with CHRF and HMV, the disease-specific SRI was an overall predictor of longterm survival in addition to established risk factors. However, the SRI predominantly beared information regarding long-term survival in non-COPD patients, while in COPD patients objective measures of the disease state were superior. This on one hand highlights the significance of HRQL in the long-term course of patients with CHRF, on the other hand it suggests that the predictive value of HRQL depends on the underlying disease.
\end{abstract}




\section{Background}

Home mechanical ventilation (HMV) is an established approach in the treatment of severe, chronic hypercapnic respiratory failure (CHRF). The number of patients treated with HMV has much increased and will rise further with medical advance and the ageing of the population [1]. However, the knowledge on clinical outcome measures during current HMV that could be valuable for long-term follow-up and for estimation of survival, is limited [2,3].

In chronic obstructive pulmonary disease (COPD), the degree of airway obstruction insufficiently represents the systemic aspects of the disease [4]. Accordingly, body mass index (BMI) and six-minute walk distance (6-MWD) have been revealed as prognostic markers [5]. Moreover, long-term survival is linked to the patients' perception of functional limitations, expressed as degree of dyspnoea [6]. There is also evidence for an association with healthrelated quality of life (HRQL) in terms of disease-specific $[7,8]$ or generic measures $[7,9]$. Intuitively, self-reported health-status has the potential to integrate diverse aspects of disease severity and prognosis [8].

Patients with CHRF might not only suffer from COPD but also from severe restrictive diseases (RD), neuromuscular disorders (NMD), or obesity-hypoventilation syndrome (OHS). In many of these patients nutritional depletion or systemic inflammation is present [10-14] and associated with survival, as in COPD [2,3], while the relationship between other measures and long-term prognosis might be different [15-17]. In addition, psycho-social factors are relevant in these chronic respiratory diseases [18-21] and could also determine long-term survival.

To account for the specific conditions of the disorders underlying CHRF, the Severe Respiratory Insufficiency (SRI) questionnaire has been introduced [22], providing a comprehensive, multidimensional picture. It can be hypothesized that this reflects features that are common in CHRF and related to prognosis, particularly under the relatively stable conditions achieved by HMV. We thus evaluated the association between disease-specific HRQL and long-term survival, comparing its predictive value with that of known risk factors. The analysis was performed in two-step manner, first identifying the role of HRQL in the total study population and then elucidating the role in patients with or without COPD.

\section{Methods}

\section{Population}

Between December 1st, 2002, and November 30th, 2004, consecutive patients with current nocturnal HMV (since $\geq$ 3 months) due to CHRF were prospectively recruited during a routine follow-up investigation. The underlying dis- eases comprised COPD, severe RD, OHS/overlap syndrome or NMD.

All patients were categorized according to their primary diagnosis upon initiation of HMV. The diagnosis of COPD relied on symptoms and airflow limitation (ratio of forced expiratory volume in one second to inspiratory vital capacity $\left.\left(\mathrm{FEV}_{1} / \mathrm{FVC}\right)<0.7\right)[23]$. OHS was characterized by $\mathrm{BMI}>30 \mathrm{~kg} / \mathrm{m}^{2}$, daytime arterial carbon dioxide tension $\left(\mathrm{PaCO}_{2}\right) \geq 45 \mathrm{mmHg}$ prior to HMV and symptoms of CHRF in the absence of other significant causes of hypoventilation based on the physician's judgement [15]. Patients with hypercapnia as a result of confirmed sleep apnoea and minor airway obstruction were classified as "overlap syndrome" (OL) [24]. Participants had to be in a stable clinical condition without signs of current exacerbation or respiratory tract infection. The study was approved by the Institutional Review Board of the University of Regensburg and patients gave their informed consent.

\section{Assessments and protocol}

Upon inclusion the SRI questionnaire, blood gases, laboratory parameters and the presence of comorbidities were assessed, as well as lung function measurements performed.

The SRI questionnaire comprises 49 questions across 7 domains covering respiratory complaints (RC), physical functioning (PF), attendant symptoms and sleep (AS), social relationship (SR), anxiety (AX), psychological wellbeing (PW), and social functioning (SF). These subscales are aggregated into one summary score (SRI-SS), whereas high values indicate high HRQL and converse [22]. For data evaluation the values obtained from the questionnaire were scaled from 0 to 100 analogous to the computation of percentages.

Capillary blood gases (Rapidlab; Bayer Inc; East Walpole, MA, USA) were analyzed during spontaneous breathing of room air if possible or otherwise during the patients' usual oxygen flow. Spirometry (MasterScreen, Viasys Inc., Würzburg, Germany) including assessment of (IVC), was performed according to ATS guidelines [25], and ERS reference values [26] were used. Among the available routine laboratory parameters which were obtained by standard procedures, we selected haemoglobin level and leukocyte number for analysis (Micros 60-CT, ABX Inc., Montpellier, France). Additionally, comorbidities as taken from the medical records or diagnosed de novo during the initial hospital stay were documented.

\section{Follow-up}

Patients were routinely admitted every 6 months for reevaluation of their respiratory status. This included the 
assessment of adverse effects of HMV treatment (leakage, dry mucosal, etc.) and treatment efficacy by a standardized procedure. Pulmonary function test were performed as described above. At this visit also ventilatory parameters were optimized, guided by nocturnal capillary blood gas values and oxygen saturation. Adherence to HMV was evaluated from the time counter readings of the ventilator and the duration of HMV was calculated in months from the day of initiation.

All patients were followed until death or the end of the study period at November $30^{\text {th }}, 2006$. In patients who could not be re-assessed in the hospital until this closing date, vital status was assessed through telephone interview of the patients' relatives and/or family doctors, or by reviewing the medical records supplied by other medical institutions. Deaths from either respiratory or any cause were recorded.

\section{Statistical analysis}

Data for continuous variables are presented as mean \pm standard deviation (SD) or as median values and quartiles, depending on whether the data showed normal distribution or not. Groups were compared by analysis of variance (ANOVA) with post hoc comparisons according to
Newman-Keuls, alternatively the unpaired t-test or the Mann-Whitney U-test for quantitative variables (with appropriate Bonferroni correction), or by Fisher's exact test for binary variables. Univariate survival analysis was performed by Kaplan-Meier analysis (log-rank test), starting by the day of inclusion to the closing date. As cut-off we used median or quartile values. Multivariate Cox regression analysis was employed to identify independent predictors. P-values $<0.05$ were considered statistically significant. All analyses were performed by the statistical software packages SPSS (version 12.0, Chicago, IL, USA) and MedCalc (version 9.2.0.1., Mariakerke, Belgium).

\section{Results \\ Patients' characteristics}

Of 262 eligible patients to whom the questionnaire was handled, 12 provided incomplete and 10 non-usable answers, while 9 patients rejected the questionnaire. Thus the study population (Table 1) comprised 231 patients (145 male, 86 female) with CHRF due to either very severe COPD $(n=98)$ of GOLD (Global Initiative for Chronic Obstructive Lung Disease [23]) stage IV, OHS/OL ( $n=54$ / $15), \operatorname{RD}(\mathrm{n}=49$; comprising chest-wall disease $(\mathrm{n}=37)$, post-tuberculosis syndrome $(n=8)$, lung fibrosis $(n=3)$, silicosis $(\mathrm{n}=1))$, or NMD $(\mathrm{n}=15)$.

Table I: Baseline characteristics of patients according to the aetiology of CHRF.

\begin{tabular}{|c|c|c|c|c|c|}
\hline Parameter & All patients & COPD & RD & NMD & OHS/OL \\
\hline $\mathrm{N}$ & 231 & 98 & 49 & 15 & 69 \\
\hline Gender (f/m) & $86 / 145$ & $28 / 70$ & $28 / 21 * *$ & $5 / 10$ & $25 / 44$ \\
\hline Age (yrs) & $62.9 \pm 10.2$ & $64.6 \pm 8.2$ & $63.2 \pm 12.0$ & $62.8 \pm 7.1$ & $60.3 \pm 11.4 * * *$ \\
\hline BMI $\left(\mathrm{kg} / \mathrm{m}^{2}\right)$ & $33.2 \pm 9.9$ & $29.4 \pm 7.0$ & $29.3 \pm 5.6$ & $28.9 \pm 10.0$ & $42.3 \pm 9.9 * * *$ \\
\hline Ventilator use $(\mathrm{h} / \mathrm{d})$ & $6.76 \pm 2.52$ & $6.70 \pm 2.81$ & $7.16 \pm 2.11$ & $7.20 \pm 2.37$ & $6.47 \pm 2.39$ \\
\hline Duration of HMV (months) & $28.9 \pm 8.8$ & $29.6 \pm 28.3$ & $45.2 \pm 36.9 *$ & $27.4 \pm 25.5$ & $32.1 \pm 25.2$ \\
\hline $\mathrm{Hb}(\mathrm{g} / \mathrm{dL})$ & $13.7 \pm 1.6$ & $13.9 \pm 1.7$ & $13.7 \pm 1.5$ & $13.7 \pm 1.2$ & $13.5 \pm 1.7$ \\
\hline Leukocyte number $\left(10^{3} / \mu \mathrm{L}\right)$ & $8.97 \pm 3.13$ & $10.1 \pm 3.5$ & $7.5 \pm 2.3 * * *$ & $7.2 \pm 2.5^{*}$ & $8.8 \pm 2.6 *$ \\
\hline Heart disease, $N(\%)$ & $65(28.1)$ & $29(29.6)$ & II (22.4) & $5(33.3)$ & $20(29.0)$ \\
\hline Diabetes, N (\%) & $4 \mid(17.7)$ & $20(20.4)$ & $4(8.1)$ & $2(13.3)$ & $15(2 \mid .7)$ \\
\hline Hyperlipidaemia, N (\%) & 27 (II.7) & II (II.2) & 7 (14.2) & I (6.7) & $8(11.6)$ \\
\hline Hypertension, N (\%) & $121(52.4)$ & $42(42.8)$ & $22(44.9)$ & $7(46.7)$ & $50(72.5)$ **** \\
\hline $\mathrm{FEV}_{1}(\mathrm{~L})$ & $1.25 \pm 0.71$ & $0.85 \pm 0.26$ & $0.89 \pm 0.34$ & $1.25 \pm 0.58 *$ & $2.08 \pm 0.68 * * *$ \\
\hline $\mathrm{FEV}_{\mathrm{I}}$ (\%pred) & $48.7 \pm 22.3$ & $32.7 \pm 8.7$ & $44.0 \pm 14.6 * *$ & $50.3 \pm 24.0 * *$ & $73.9 \pm 17.1 * * *$ \\
\hline FEV/IVC (\%) & $61.9 \pm 17.8$ & $45.8 \pm 9.2$ & $74.3 \pm 9.9 * * *$ & $87.4 \pm 17.2 * * *$ & $70.3 \pm 11.4 * * *$ \\
\hline IVC (L) & $2.05 \pm 0.95$ & $1.91 \pm 0.55$ & $1.19 \pm 0.44 * * *$ & $1.44 \pm 0.66 * *$ & $2.98 \pm 0.94 * * *$ \\
\hline IVC (\%pred) & $70.0 \pm 21.2$ & $56.3 \pm 13.9$ & $48.4 \pm 16.5 * *$ & $46.2 \pm 22.6 *$ & $82.8 \pm 16.3 * * *$ \\
\hline $\mathrm{pH}$ & $7.42 \pm 0.04$ & $7.42 \pm 0.03$ & $7.42 \pm 0.04$ & $7.43 \pm 0.03$ & $7.43 \pm 0.04$ \\
\hline $\mathrm{PaO}_{2}(\mathrm{mmHg})$ & $68.0 \pm 16.0$ & $66.8 \pm 16.2$ & $71.1 \pm 18.1$ & $69.2 \pm 19.1$ & $67.2 \pm 13.3$ \\
\hline $\mathrm{PaCO}_{2}(\mathrm{mmHg})$ & $44.2 \pm 6.8$ & $46.4 \pm 6.7$ & $44.7 \pm 6.6$ & $40.5 \pm 6.0^{* *}$ & $41.6 \pm 6.2 * * *$ \\
\hline $\mathrm{BE}(\mathrm{mmol} / \mathrm{L})$ & $3.93 \pm 3.04$ & $4.76 \pm 3.33$ & $3.84 \pm 2.57$ & $2.86 \pm 2.06^{*}$ & $3.06 \pm 2.81 * *$ \\
\hline
\end{tabular}

Data are shown as mean \pm SD. Characteristics of patients with COPD were compared with those of patients with other diseases using the unpaired t-test, Mann-Whitney U-test, or Fisher's exact test. P-values for individual tests were $*_{p}<0.05$; ** $p<0.017$ (corresponding to an overall $p<0.05$ using a Bonferroni correction for three comparisons); $*_{*}^{*} \mathrm{p}<0.00 \mathrm{I}$. Definition of abbreviations: COPD $=$ chronic obstructive pulmonary disease; RD = restrictive disease; $\mathrm{NMD}=$ neuromuscular disease; OHS = obesity-hypoventilation syndrome; OL = overlap syndrome: $\mathrm{BMI}=$ body-mass index; $\mathrm{HMV}=$ home mechanical ventilation; $\mathrm{Hb}=$ haemoglobin; $\mathrm{FEV}_{1}=$ forced expiratory volume in one second; $\mathrm{IVC}^{=}$inspiratory vital capacity; $\mathrm{PaO}_{2}=$ arterial oxygen tension; $\mathrm{PaCO}_{2}=$ arterial carbon dioxide tension; $\mathrm{BE}=$ base excess. Blood gas parameters were obtained while patients were breathing room air $(n=147)$ or their usual oxygen flow $(n=84)$. 
Home ventilators were set at a volume- or pressure-cycled assist-controlled mode. Patients were ventilated via nasal $(95.2 \%)$ or full-face $(3.1 \%)$ mask or tracheostomy (1.7\%). Median (quartiles) expiratory pressure was 4 (3; 5) $\mathrm{cmH}_{2} \mathrm{O}$, inspiratory pressure $20(18 ; 24) \mathrm{cmH}_{2} \mathrm{O}$, and respiratory frequency $19(16 ; 22) / \mathrm{min}$. Patients had spent $25.1(8.1 ; 49.7)$ months on nocturnal HMV prior to enrolment; ventilator use was $6.8(4.8 ; 8.3) \mathrm{h} /$ day. Long term oxygen therapy (LTOT) was administered in $81 \%$ of patients (96\% COPD, 70\% RD, 53\% NMD, 74\% OHS/ OL).

SRI-SS differed significantly between groups (ANOVA, $\mathrm{p}<$ 0.001; Table 2), specifically between COPD (52.5 \pm 15.6$)$ and non-COPD $(67.6 \pm 16.4 ; \mathrm{p}<0.001)$. According to Newman-Keuls there were two homogeneous groups for SRI-SS: COPD showed similar values as NMD, and RD similar values as OHS/OL. SRI-SS was not different between OL and OHS ( $\mathrm{p}=0.491)$. Values did also not differ between male and female or non-invasively ventilated and tracheostomised $(n=4)$ patients, nor depend on the fact whether nasal or face masks were used nor whether patients had LTOT nor not. The subdomains showed very similar results as the SRI-SS (Table 2).

\section{Long-term survival and prognostic factors in the total population}

In the total population $(\mathrm{n}=231)$, the mean observation time was $28.9 \pm 8.8$ months, ranging from 0.2 (death one week after discharge) to 45.8 months. During the study period, 44 patients died (overall mortality 19.1\%; COPD $31.6 \%(n=31)$, non-COPD 9.8\% (OHS $n=7$, RD $n=6)$ ), either from respiratory $(\mathrm{n}=29 ; 65.9 \%)$, or non-respiratory $(\mathrm{n}=3 ; 6.8 \%)$, or not further specified causes $(\mathrm{n}=12$; $27.3 \%)$.

In the total population survival rates (standard error) at 1 , 2 and 3 years were 93.1 (1.7), 84.3 (2.4), and 78.4 (3.0)
$\%$, respectively. In COPD, the respective values were 85.7 (3.5), 72.4 (4.5) and 65.3 (5.3) \%, and in non-COPD 98.5 (1.1), 93.1 (2.2), and 88.1 (3.2) \%. Survival differed between COPD and non-COPD ( $<<0.001$; HR 0.266; 95\%-CI 0.139-0.508), but not between NMD, OHS/OL, or RD. The fact whether patients were ventilated via nasal, full-face mask or tracheostomy was not related to survival, similarly as for LTOT.

In univariate analyses, BMI, leukocyte number, base excess (BE), $\mathrm{FEV}_{1}$ and $\mathrm{FEV}_{1} / \mathrm{IVC}$ were significantly associated with survival in the total population (Table 3 ). Neither gender nor comorbidities including heart disease, diabetes, hyperlipidaemia and systemic hypertension, nor medication were related to survival. Regarding SRI, all subscores, with the exception of attendant symptoms and sleep (AS), were predictors of survival (Table 3). Accordingly, SRI-SS was predictive when using the median (Figure 1, panel A) or quartile values (Figure 1, panel B) as cutoff.

Stepwise multivariate Cox regression analysis, including the quantitative factors identified in univariate analyses (BMI, leukocytes, BE, $\mathrm{FEV}_{1}, \mathrm{FEV}_{1} / \mathrm{IVC}$, SRI-SS) revealed as independent predictors in the total population leukocyte number (HR 2.693, 95\%-CI 1.349-5.375; p = 0.005), $\mathrm{FEV}_{1}$ (HR 0.313, 95\%-CI 0.152-0.644; p = 0.002) and SRI-SS (HR 0.383, 95\%-CI 0.186-0.789; p = 0.009). To assess whether the difference in survival between COPD and non-COPD influenced this result, the analysis was repeated by including disease category as binary (COPD versus non-COPD) variable. Again, $\mathrm{FEV}_{1}$, SRI-SS and leukocytes were independent risk factors ( $p<0.05)$, whereas disease category did not show any more a significant association in this multivariate analysis $(\mathrm{p}=0.192)$. When disease category was added as variable to each of the other variables in separate analyses, these variables were still predictors in addition to the disease ( $\mathrm{p}<0.05$ each).

Table 2: Results of SRI questionnaire within subgroups.

\begin{tabular}{|c|c|c|c|c|c|}
\hline SRI - subscore & All $(n=231)$ & COPD $(n=98)$ & $\operatorname{RD}(n=49)$ & NMD (n = 15) & $\mathrm{OHS} / \mathrm{OL}(\mathrm{n}=69)$ \\
\hline Respiratory complaints & $61.2 \pm 19.8$ & $50.9 \pm 17.5$ & $65.8 \pm 17.7^{* * *}$ & $59.4 \pm 13.9 *$ & $72.3 \pm 18.7^{* * * *}$ \\
\hline Physical functioning & $49.4 \pm 24.9$ & $38.2 \pm 21.6$ & $55.0 \pm 24.7^{* *}$ & $33.6 \pm 18.0$ & $64.2 \pm 22.0 * * *$ \\
\hline Attendant symptoms/sleep & $63.6 \pm 19.0$ & $58.9 \pm 18.2$ & $65.8 \pm 19.4$ & $59.0 \pm 16.5$ & $69.4 \pm 19.1^{* * *}$ \\
\hline Social relationship & $71.9 \pm 18.5$ & $64.9 \pm 19.9$ & $75.8 \pm 14.6^{* *}$ & $68.8 \pm 14.3$ & $79.3 \pm 16.5^{* * * *}$ \\
\hline Anxiety & $62.5 \pm 23.6$ & $51.8 \pm 21.6$ & $66.9 \pm 24.2^{* *}$ & $61.7 \pm 19.1$ & $74.1 \pm 20.7^{* * *}$ \\
\hline Psychological wellbeing & $62.9 \pm 19.6$ & $55.7 \pm 19.2$ & $68.3 \pm 19.0^{* * *}$ & $53.6 \pm 12.7$ & $70.9 \pm 17.4^{* * *}$ \\
\hline Social functioning & $58.2 \pm 23.3$ & $47.3 \pm 20.9$ & $66.2 \pm 23.7^{* * * *}$ & $50.3 \pm 16.6$ & $68.8 \pm 21.5 * * *$ \\
\hline Summary score & $61.2 \pm 17.7$ & $52.2 \pm 15.6$ & $66.2 \pm 17.2^{* * *}$ & $55.3 \pm 9.2$ & $71.3 \pm 15.7^{* * *}$ \\
\hline
\end{tabular}

Definition of abbreviations: SRI = Severe Respiratory Insufficiency Questionnaire; COPD = chronic obstructive pulmonary disease; RD = restrictive disease; NMD = neuromuscular disease; OHS = obesity-hypoventilation syndrome; OL = sleep apnoea syndrome. Mean values and SD of HRQL are given, and differences between COPD and the other groups were compared by the t-test, as values were normally distributed within groups. * $<0.05 ; *^{*} p<0.017$ (overall $p<0.05$ according to Bonferroni correction); ***p $<0.001$. 


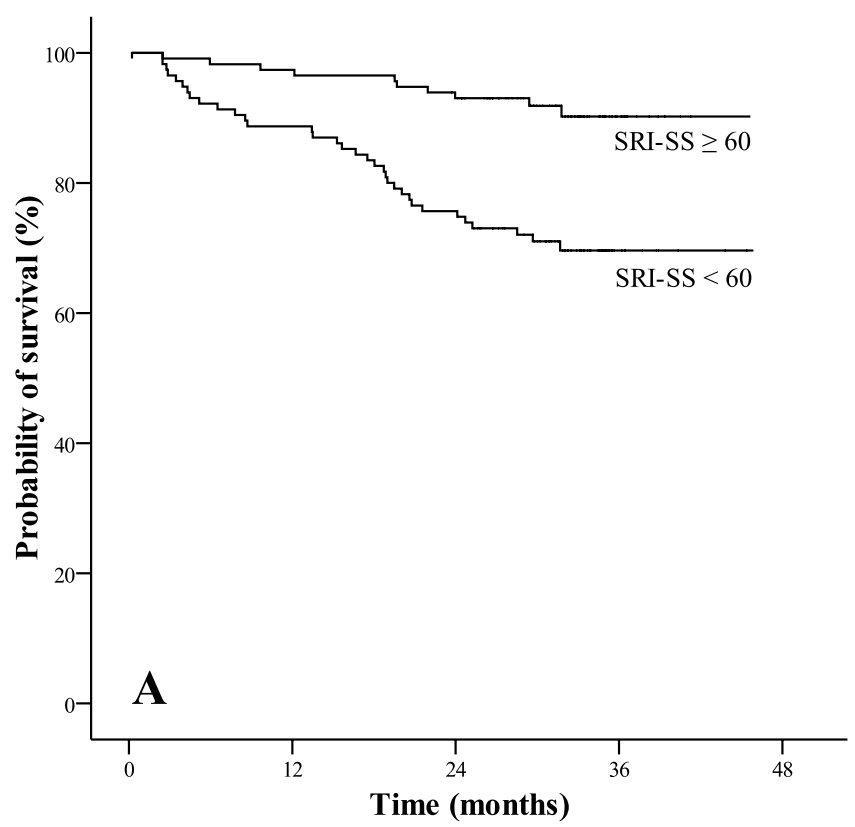

Number of patients at risk:

$\begin{array}{lllll}\begin{array}{c}\text { SRI-SS } \\ 115\end{array} & 112 & 106 & 15 & 0 \\ \begin{array}{c}\text { SRI-SS }<60 \\ 116\end{array} & 102 & 87 & 10 & 0\end{array}$

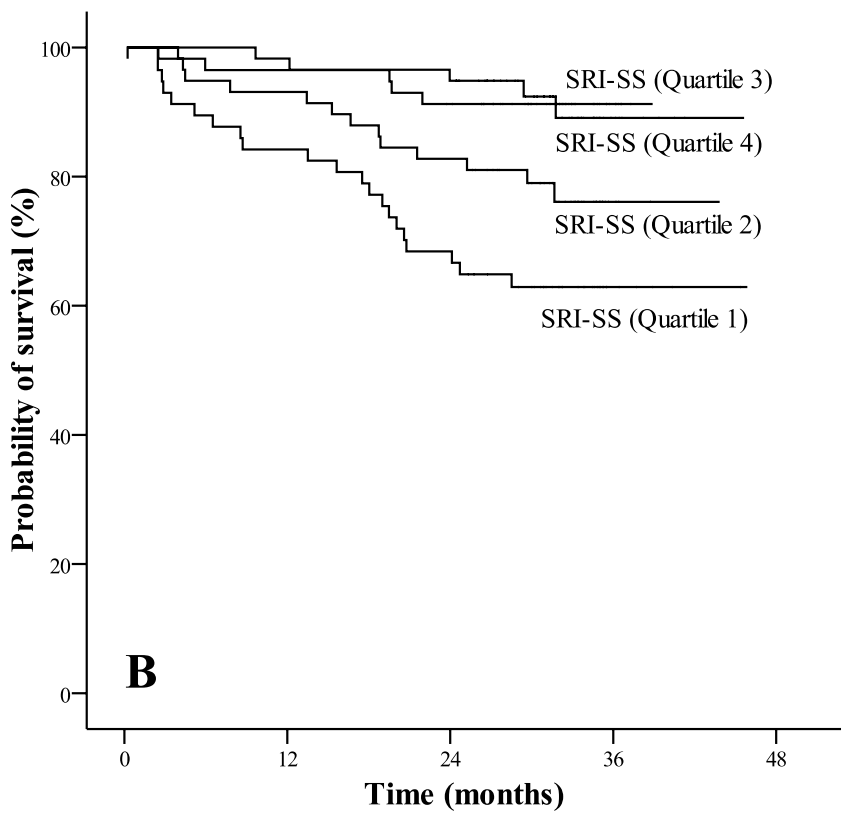

Number of patients at risk:

\begin{tabular}{cc}
\multicolumn{2}{l}{ Quartile } \\
1 & 57 \\
2 & 59 \\
3 & 57 \\
4 & 58
\end{tabular}

$\begin{array}{ll}57 & 48 \\ 59 & 54 \\ 57 & 55 \\ 58 & 57\end{array}$

39
48
51
56

$\begin{array}{ll}7 & 0 \\ 4 & 0 \\ 7 & 0 \\ 8 & 0\end{array}$

\section{Figure I}

Prognostic value of HRQL in the total population of patients $(n=23 I)$ using the median (Panel A; SRI-SS 60.0) as cut-off value (HR 0.262; 95\%-Cl 0.I29-0.530; $\mathrm{p}<0.00 \mathrm{I}$ ) or the quartiles (Panel B; 0-49.7, quartile I; 49.7-60.0, quartile 2; 60.0-74.9, quartile 3; > 74.9, quartile 4; log rank; HR 0.533; 95\%-Cl 0.394-0.722; $\mathrm{p}<0.00 \mathrm{I}$ ).

\section{Prognostic factors in COPD patients}

When analysing the data of COPD separately $(\mathrm{n}=98)$, $\mathrm{FEV}_{1}\left(75^{\text {th }}\right.$ percentile $\left.1.04 \mathrm{~L}, \mathrm{p}<0.012\right)$, BMI $\left(75^{\text {th }}\right.$ percentile $\left.33.9 \mathrm{~kg} / \mathrm{m}^{2}, \mathrm{p}<0.009\right)$ but neither SRI subdomains nor SRI-SS were associated with survival; also leukocyte number did not reach statistical significance (median 9.6 $\left.{ }^{*} 10^{3} / \mu \mathrm{L}, \mathrm{p}=0.059\right)$.

\section{Prognostic factors in non-COPD patients}

In contrast, in non-COPD patients SRI-RC, SRF-PF, SRI$\mathrm{SR}$, SRI-PW and SRI-SF using the $25^{\text {th }}$ percentile $(\mathrm{p}<0.01$, each), and SRI-RC, SRI-SR, SRI-PW, SRI-SF using the $50^{\text {th }}$ percentile $(\mathrm{p}<0.05$ each $)$, as well as SRI-SS $\left(25^{\text {th }}\right.$ and $50^{\text {th }}$ percentile; $\mathrm{p}=0.009$ and $\mathrm{p}=0.039$ respectively) were linked to survival. Additionally leukocyte number was a predictor of long-term survival $\left(75^{\text {th }}\right.$ percentile $10.0^{*} 10^{3} /$ $\mu \mathrm{L} ; \mathrm{p}=0.012)$. When the analysis was repeated in nonCOPD patients by excluding NMD, the results regarding SRI subdomains and SRI-SS became even more pronounced despite the reduction in sample size, while leu- kocytes remained as a predictor $\left(50^{\text {th }}\right.$ percentile $7.8 * 10^{3} /$ $\mu \mathrm{L} ; \mathrm{p}=0.034 ; 75^{\text {th }}$ percentile $\left.10.1 * 10^{3} / \mu \mathrm{L} ; \mathrm{p}=0.048\right)$.

\section{Discussion}

The present study indicated that in patients with CHRF treated with HMV, specific HRQL assessed by the SRI questionnaire was an independent predictor of long-term survival. Especially in non-COPD patients who showed a favourable survival compared to COPD, the SRI summary score and most of the subscores were associated with prognosis. In COPD, the predictive power of SRI for survival was inferior compared to biological measures. These results suggest that self-reported health-status reflects disease characteristics that are relevant for prognosis and not contained in physiological measures.

HMV is considered to improve long-term survival in various diseases presenting with CHRF $[15,21,27,28]$ but only few useful measures are currently known for monitoring CHRF during treatment with HMV $[2,3,15,17]$. To our knowledge, the present study is novel in assessing disease- 
Table 3: Risk factors according to univariate survival analyses in the total population of patients $(n=23 I)$.

\begin{tabular}{|c|c|c|c|c|}
\hline Variable & Median (Quartile) & $\mathrm{p}$-value§ & HR & $95 \%-\mathrm{Cl}$ of $\mathrm{HR}$ \\
\hline Disease category ${ }^{+}$ & - & $<0.001$ & 0.266 & $0.139-0.508$ \\
\hline $\operatorname{Sex}(m / f)$ & - & 0.091 & 1.803 & $0.911-3.568$ \\
\hline Age (yrs) & 65.4 (57.I; 70.4) & 0.074 & 1.745 & $0.940-3.238$ \\
\hline $\mathrm{BMI}\left(\mathrm{kg} / \mathrm{m}^{2}\right)$ & $31.6\left(26.9 ; 38.2^{* *}\right)$ & 0.006 & 0.420 & $0.223-0.792$ \\
\hline Leukocytes $\left(10^{3} / \mu \mathrm{L}\right)$ & $8.6\left(6.6^{*} ; 10.6 *\right)$ & 0.002 & 2.745 & $1.4 \mid 4-5.332$ \\
\hline $\mathrm{BE}(\mathrm{mmol} / \mathrm{L})$ & $3.70\left(2.00 ; 5.50^{* * * *}\right)$ & 0.027 & 1.991 & $1.067-3.715$ \\
\hline $\mathrm{FEV}_{1}(\mathrm{~L})$ & $1.03(0.76 ; 1.59 *)$ & $<0.001$ & 0.267 & $0.131-0.544$ \\
\hline FEV (\%pred) & $42.1\left(31.9^{* *} ; 63.5^{*}\right)$ & 0.001 & 0.351 & $0.179-0.686$ \\
\hline $\operatorname{IVC}(\mathrm{L})$ & $1.84(1.38 ; 2.56)$ & 0.112 & 0.617 & $0.338-1.125$ \\
\hline IVC (\%pred) & $60.8\left(45.9 ; 76.1^{*}\right)$ & 0.205 & 0.665 & $0.352-1.255$ \\
\hline FEV/IVC (\%) & $62.0(47.0 ; 76.0)$ & 0.001 & 0.950 & $0.920-0.981$ \\
\hline SRI-RC & 62.5 (46.9*; 75.0**) & $<0.001$ & 0.280 & $0.142-0.554$ \\
\hline SRI-PF & $50.0\left(33.3 * ; 70.0^{*}\right)$ & 0.002 & 0.379 & $0.198-0.724$ \\
\hline SRI-AS & $64.3(53.6 ; 75.0)$ & 0.124 & 0.629 & $0.342-1.142$ \\
\hline SRI-SR & $75.0\left(58.3^{* * ;} ; 83.3^{*}\right)$ & 0.002 & 0.381 & $0.202-0.718$ \\
\hline SRI-AX & $65.0(45.0 * ; 80.0 *)$ & 0.006 & 0.420 & $0.223-0.793$ \\
\hline SRI-PW & $61.1(50.0 * * ; 77.8)$ & 0.012 & 0.464 & $0.251-0.857$ \\
\hline SRI-SF & 56.3 (40.6*; 75.0*) & 0.002 & 0.374 & $0.198-0.705$ \\
\hline SRI-SS & $60.0\left(49.7^{* * ;} ; 74.9^{*}\right)$ & $<0.001$ & 0.262 & $0.129-0.530$ \\
\hline
\end{tabular}

Median values and quartiles are given for the total population, as values were not normally distributed due to the pooling of groups. ${ }^{+}$COPD vs. non-COPD. $\S$ according to univariate survival analyses (log-rank) using the respective median value. Additionally, $25^{\text {th }}$ and $75^{\text {th }}$ percentiles were used. ${ }^{*}<<0.05$; ${ }^{* *} \mathrm{p}<0.0 \mathrm{I}$; ${ }^{* * *} \mathrm{p}<0.00 \mathrm{I}$. Definition of abbreviations: $\mathrm{HR}=$ hazard ratio for survival; $\mathrm{Cl}=\mathrm{Confidence} \mathrm{interval;} \mathrm{BMI}=$ body-mass index; $\mathrm{BE}$ = base excess; $\mathrm{FEV}_{1}$ = forced expiratory volume in one second; IVC = inspiratory vital capacity; SRI = Severe Respiratory Insufficiency Questionnaire; RC = Respiratory Complaints; PF = Physical Functioning; AS = Attendant symptoms and Sleep; $S R=$ Social Relationships; $A X=$ Anxiety; WB = Psychological Well-being; SF = Social Functioning. SS = Summary Score.

specific HRQL in relation to long-term survival in these patients. The observation period covered $2-4$ years in a large population of COPD, NMD, RD, or OHS/OL. Irrespective of their different aetiologies, patients constituted a fairly homogeneous group, as those treated with HMV for $<3$ months were excluded and in $98 \%$ of patients ventilation was non-invasive. Noteworthy enough, the mode of ventilation had no impact on survival.

Most studies on the impact of HRQL in CHRF have utilized non-specific measures such as the Sickness Impact Profile (SIP) $[19,20]$, Health Index (HI) [19], Sense of Coherence (SOC) [19], Nottingham Health Profile (NHP), or SF-36 [21]. Moreover, these studies predominantly enrolled patients with restrictive disease, such as NMD, post-polio syndrome, or kyphoscoliosis. Recent data, however, indicate that COPD became a major indication for HMV, representing a proportion of 34\% [1]. As in our study $42 \%$ of patients had COPD, our results seem to reflect very well the frequency distribution regarding the current clinical use of this treatment.

Patients with CHRF suffer from functional impairment and respiratory symptoms, but specifically from the sequels of CHRF such as daytime sleepiness, morning headache and sleep disturbances. To account for their specific conditions of their daily life, the Maugeri Foundation Respiratory Failure item set (MRF-28) has been developed
[18] and shown to be useful. This referred primarily to COPD, as the study included only 17 patients with kyphoscoliosis. More recently, the SRI questionnaire has been validated in a large population of patients $(n=226)$ for the assessment of HRQL in CHRF and HMV [22]. Based on this it has also been employed in the present investigation. In line with previous data [19-22], we found significant differences in HRQL between disease categories. Regarding the SRI summary score, HRQL was most impaired in COPD or NMD, and showed highest values in OHS/OL.

To assess the role of the SRI relative to other measures, we first analyzed the data of the total population of patients. Specific HRQL was an independent predictor of survival, in addition to $\mathrm{FEV}_{1}$ and systemic inflammation in terms of leukocyte number. Thus, these results indicate that in patients with CHRF and HMV, HRQL provides valuable information for long-term survival beyond that of biological predictors $[2,3]$. In a large study of 446 patients with end-stage lung disease of different aetiologies receiving LTOT and/or HMV, C-reactive protein (CRP) and BMI were revealed as important prognostic factors [3]. Instead of CRP we evaluated leukocyte number which was similarly associated with mortality, suggesting a link to systemic inflammation, as in cardiovascular diseases $[15,29]$. Surprisingly, the prognostic value of BMI was weak in our study, presumably as the BMI-associated risk in OHS or 
OL is different from that in COPD [15]. In line with this, BMI was predictive for long-term survival when patients with COPD were analyzed separately.

In a second step we evaluated SRI separately in the two major groups of patients comprising a sample size sufficient for survival analysis (COPD and non-COPD). This was even more relevant, as HRQL differs between diseases in CHRF $[19,20,22]$, in accordance with our data. It thus might be suspected that the association with HRQL was due to differences of survival rate between diseases that paralleled those of HRQL. Indeed, and in line with the literature $[21,30]$, mortality was highest in COPD, while it was lower and rather similar in the other diseases. Irrespective of this, the adjusted multivariate analysis suggested that the differences in survival between groups were primarily attributable to the differences in the prognostic measures. Moreover, when patients with COPD were excluded, SRI-SS and nearly all subdomains were highly predictive for survival. In NMD, HRQL was impaired similarly as in COPD; thus these patients were not quite comparable to the other non-COPD groups. Omission of NMD even improved the results regarding the association between long-term survival and HRQL. It seems likely that the low level of HRQL as well as elevated mortality in COPD indicated the impact of multimorbidity that is often present in this disease.

The weak association between HRQL and long-term survival in COPD may have been the result of different factors. The average score of some subdomains in this group was possibly too low to provide sufficient range for the assertion of significant associations. Clinical experience also shows that $\mathrm{HMV}$ is often perceived as cumbersome in COPD, impairing HRQL. In fact, the predictive value of HRQL for long-term survival in COPD is still controversial. While the COPD-specific St. George Respiratory Questionnaire (SGRQ) was associated with long-term mortality across different severities of airflow limitation $[7,8]$, the Chronic Respiratory Questionnaire (CRQ) was not related to 3-year survival after pulmonary rehabilitation in a population comprising mainly COPD [31]. Noteworthy enough, the CRQ does not cover physical disability [7], an important prognostic factor in COPD [5]. In line with this, the present investigation showed a tendency towards an association between the SRI subdomain "physical functioning" and mortality in COPD (KaplanMeier; $p=0.10$, data not shown). Taken together, the findings suggest that the prognostic value of a questionnaire in patients with CHRF much depends on disease-specific features, as reflected in different relative weights of subdomains. It is reassuring in this respect that dyspnoea scores, which comprise a grading of functional capacity or respiratory symptoms, such as the Modified Medical Research Council (MMRC) Score, Borg Scale or Breathing
Problems Questionnaire (BPQ), appear particularly informative with regard to disease severity and its relation to mortality $[6,31]$.

In non-COPD patients, low HRQL was related to increased mortality. Accordingly, in COPD mortality was high and HRQL low. In this respect there was as link between HRQL and mortality in all diseases associated with CHRF and HMV although in COPD biological measures dominated. Apparently, self-reported health status provides a comprehensive picture which under these circumstances is more informative beyond biological indices. Indeed, correlations between HRQL and lung function were weak in the majority of cases $[32,33]$.

The present study, though being prospective, was subject to some limitations. The number of patients included was large but still small compared to the number of deaths. It is, however, elucidating that SRI turned out to be predictive particularly in the group of non-COPD patients despite the lower mortality rate that limited the power of the study. As blood gas values were mostly assessed during LTOT, the assessment of their value, especially for arterial oxygen tension, was probably biased. Moreover, 6-min walk distance (6-MWD), an important indicator in COPD, was not included, as it could not be assessed in all patients due to inability or paralysis. However, it might be of interest that there is evidence for an association between 6-MWD and subjective factors [33] and that therefore part of the predictive value of 6-MWD might have been contained in the SRI. Of course, HRQL can be no more than one factor in the multivariate panel determining the clinical state and prognosis of patients with CHRF.

\section{Conclusion}

In summary, our findings provided evidence that in patients with CHRF and current HMV disease-specific HRQL as quantified by the SRI questionnaire was associated with long-term survival but that its predictive value depended on the underlying disease. Thus, disease- specific HRQL bears additional information for long-term outcome beyond that supplied by physiological measures. This information might be useful for the assessment and routine monitoring of patients with CHRF, rendering the picture of impaired health more precise through inclusion of the patients' perception.

\section{Abbreviations}

BE: Base excess;

BMI: Body mass index;

BPQ: Breathing Problems Questionnaire; 
COPD: Chronic obstructive pulmonary disease;

CHRF: Chronic hypercapnic respiratory failure;

CRQ: Chronic Respiratory Questionnaire;

$\mathrm{FEV}_{1:}$ Forced expiratory volume in one second;

HI: Health-Index;

HRQL: Health-related quality of life;

HMV: Home mechanical ventilation;

LTOT: Long-term oxygen therapy;

MMRC: Modified Medical Research Council;

MRF-28: Maugeri Foundation Respiratory questionnaire;

NMD: Neuromuscular disorder;

NHP: Nottingham Health Profile;

OHS: Obesity-hypoventilation syndrome;

OL: Overlap syndrome;

$\mathrm{PaCO}_{2}$ : Arterial carbon dioxide tension;

$\mathrm{PaO}_{2:}$ Arterial oxygen tension;

RD: Restrictive disease;

SD: Standard deviation;

SIP: Sickness Impact Profile;

SGRQ: St. George Respiratory Questionnaire;

SOC: Sense of Coherence;

SRI: Severe respiratory insufficiency questionnaire;

SRI-RC: SRI subdomain respiratory complaints;

SRI-PF: SRI subdomain physical functioning;

SRI-AS: SRI subdomain attendant symptoms and sleep;

SRI-SR :SRI subdomain social relationship;

SRI-AX: SRI subdomain anxiety;

SRI-PW: SRI subdomain psychological wellbeing;
SRI-SF: SRI subdomain social functioning;

SRI-SS: SRI summary score;

6-MWD: Six-minute walk distance;

VC: Vital capacity.

\section{Competing interests}

The author(s) declare that they have no competing interests.

\section{Authors' contributions}

SB designed the study, performed part of the data evaluation and participated in writing the manuscript. APH collected a large part of the data, performed part of the data evaluation and helped in writing. RAJ participated in the statistical evaluation of the data, their interpretation and in writing the manuscript. KS and FH collected part of the data and participated in interpreting the data. MP enabled the realization of the study, supervised its performance and participated in data interpretation. All authors had full access to all the data in the study and take responsibility for the integrity of the data and the accuracy of the data analysis.

\section{References}

I. Lloyd-Owen SJ, Donaldson GC, Ambrosino N, Escarabill J, Farre R, Fauroux B, Robert D, Schoenhofer B, Simonds AK, Wedzicha JA: Patterns of home mechanical ventilation use in Europe: results from the Eurovent survey. Eur Respir J 2005, 25: $1025-103 \mid$.

2. Chailleux E, Fauroux B, Binet F, Dautzenberg B, Polu JM: Predictors of survival in patients receiving domiciliary oxygen therapy or mechanical ventilation. A I0-year analysis of ANTADIR Observatory. Chest 1996, 109:741-749.

3. Cano NJ, Pichard C, Roth H, Court-Fortune I, Cynober L, GerardBoncompain M, Cuvelier A, Laaban JP, Melchior JC, Raphael JC, Pison $C M$ : C-reactive protein and body mass index predict outcome in end-stage respiratory failure. Chest 2004, I 26:540-546.

4. Agusti AG, Noguera A, Sauleda J, Sala E, Pons J, Busquets X: Systemic effects of chronic obstructive pulmonary disease. Eur Respir J 2003, 2 1:347-360.

5. Celli BR, Cote CG, Marin JM, Casanova C, Montes dO, Mendez RA, Pinto PV, Cabral HJ: The body-mass index, airflow obstruction, dyspnea, and exercise capacity index in chronic obstructive pulmonary disease. N Engl J Med 2004, 350:1005-1012.

6. Nishimura K, Izumi T, Tsukino M, Oga T: Dyspnea is a better predictor of 5-year survival than airway obstruction in patients with COPD. Chest 2002, I 2 I: | 434-1440.

7. Oga T, Nishimura K, Tsukino M, Sato S, Hajiro T: Analysis of the factors related to mortality in chronic obstructive pulmonary disease: role of exercise capacity and health status. Am J Respir Crit Care Med 2003, 167:544-549.

8. Domingo-Salvany A, Lamarca R, Ferrer M, Garcia-Aymerich J, Alonso J, Felez M, Khalaf A, Marrades RM, Monso E, Serra-Batlles J, Anto JM: Health-related quality of life and mortality in male patients with chronic obstructive pulmonary disease. Am J Respir Crit Care Med 2002, I 66:680-685.

9. Anthonisen NR, Wright EC, Hodgkin JE: Prognosis in chronic obstructive pulmonary disease. Am Rev Respir Dis 1986, 133:| 4-20.

10. Cano NJ, Roth H, Court-Ortune I, Cynober L, Gerard-Boncompain M, Cuvelier A, Laaban JP, Melchior JC, Pichard C, Raphael JC, Pison $C M$ : Nutritional depletion in patients on long-term oxygen 
therapy and/or home mechanical ventilation. Eur Respir / 2002, 20:30-37.

II. Dahl M, Vestbo J, Lange P, Bojesen SE, Tybjaerg-Hansen A, Nordestgaard BG: C-reactive protein as a predictor of prognosis in chronic obstructive pulmonary disease. Am J Respir Crit Care Med 2007, 175:250-255.

12. de Torres JP, Cordoba-Lanus E, Lopez-Aguilar C, Muros dF, Montejo dG, Aguirre-Jaime A, Celli BR, Casanova C: C-reactive protein levels and clinically important predictive outcomes in stable COPD patients. Eur Respir J 2006, 27:902-907.

13. Man SF, Connett JE, Anthonisen NR, Wise RA, Tashkin DP, Sin DD: C-reactive protein and mortality in mild to moderate chronic obstructive pulmonary disease. Thorax 2006, 61:849-853.

14. Budweiser S, Meyer K, Jorres RA, Heinemann F, Wild PJ, Pfeifer M: Nutritional depletion and its relationship to respiratory impairment in patients with chronic respiratory failure due to COPD or restrictive thoracic diseases. Eur J Clin Nutr 2007 in press. doi: 10.1038/sj.ejcn. 1602708 .

15. Budweiser S, Riedel SG, Jorres RA, Heinemann F, Pfeifer M: Mortality and prognostic factors in patients with obesity-hypoventilation syndrome undergoing noninvasive ventilation. J Intern Med 2007, 261:375-383.

16. Budweiser S, Jorres RA, Riedl T, Heinemann F, Hitzl AP, Windisch W, Pfeifer M: Predictors of survival in chronic hypercapnic patients with COPD undergoing non-invasive home ventilation. Chest 2007, 13 I:1650-1658.

17. Budweiser S, Murbeth RE, Jorres RA, Heinemann F, Pfeifer M: Predictors of long-term survival in patients with restrictive thoracic disorders and chronic respiratory failure undergoing non-invasive home ventilation. Respirology 2007, I 2:55 I-559.

18. Carone M, Bertolotti G, Anchisi F, Zotti AM, Donner CF, Jones PW: Analysis of factors that characterize health impairment in patients with chronic respiratory failure. Quality of Life in Chronic Respiratory Failure Group. Eur Respir J 1999, 13:1293-1300.

19. Markstrom A, Sundell K, Lysdahl M, Andersson G, Schedin U, Klang B: Quality-of-life evaluation of patients with neuromuscular and skeletal diseases treated with noninvasive and invasive home mechanical ventilation. Chest 2002, 122:1695-1700.

20. Pehrsson K, Olofson J, Larsson S, Sullivan M: Quality of life of patients treated by home mechanical ventilation due to restrictive ventilatory disorders. Respir Med 1994, 88:2I-26.

21. Simonds AK, Elliott MW: Outcome of domiciliary nasal intermittent positive pressure ventilation in restrictive and obstructive disorders. Thorax 1995, 50:604-609.

22. Windisch W, Freidel K, Schucher B, Baumann H, Wiebel M, Matthys H, Petermann F: The Severe Respiratory Insufficiency (SRI) Questionnaire: a specific measure of health-related quality of life in patients receiving home mechanical ventilation. J Clin Epidemiol 2003, 56:752-759.

23. Rabe KF, Hurd S, Anzueto A, Barnes PJ, Buist SA, Calverley P, Fukuchi Y, Jenkins C, Rodriguez-Roisin R, van Weel C, Zielinski J: Global strategy for the diagnosis, management, and prevention of chronic obstructive pulmonary disease: GOLD executive summary. Am J Respir Crit Care Med 2007, I 76:532-555.

24. Chaouat A, Weitzenblum E, Krieger J, Ifoundza T, Oswald M, Kessler $\mathrm{R}$ : Association of chronic obstructive pulmonary disease and sleep apnea syndrome. Am J Respir Crit Care Med 1995, I 5 I:82-86.

25. Standardization of Spirometry, 1994 Update. American Thoracic Society. Am J Respir Crit Care Med 1995, I 52: I I 07-I I 36.

26. Quanjer PH, Tammeling GJ, Cotes JE, Pedersen OF, Peslin R, Yernault JC: Lung volumes and forced ventilatory flows. Report Working Party Standardization of Lung Function Tests, European Community for Steel and Coal. Official Statement of the European Respiratory Society. Eur Respir J Suppl 1993, 16:5-40.

27. Bourke SC, Tomlinson M, Williams TL, Bullock RE, Shaw PJ, Gibson G]: Effects of non-invasive ventilation on survival and quality of life in patients with amyotrophic lateral sclerosis: a randomised controlled trial. Lancet Neurol 2006, 5: I40-I47.

28. Gustafson T, Franklin KA, Midgren B, Pehrsson K, Ranstam J, Strom $\mathrm{K}$ : Survival of patients with kyphoscoliosis receiving mechanical ventilation or oxygen at home. Chest 2006, 130:1828-1833.

29. Margolis KL, Manson JE, Greenland P, Rodabough RJ, Bray PF, Safford M, Grimm RH Jr, Howard BV, Assaf AR, Prentice R: Leukocyte count as a predictor of cardiovascular events and mortality in postmenopausal women: the Women's Health Initiative Observational Study. Arch Intern Med 2005, 165:500-508.

30. Janssens JP, Derivaz S, Breitenstein E, De Muralt B, Fitting JW, Chevrolet JC, Rochat $\mathrm{T}$ : Changing patterns in long-term noninvasive ventilation: a 7-year prospective study in the Geneva Lake area. Chest 2003, I 23:67-79.

31. Gerardi DA, Lovett L, Benoit-Connors ML, Reardon JZ, ZuWallack RL: Variables related to increased mortality following outpatient pulmonary rehabilitation. Eur Respir J 1996, 9:43 I-435.

32. Jones PW: Health status measurement in chronic obstructive pulmonary disease. Thorax 200I, 56:880-887.

33. Wegner RE, Jorres RA, Kirsten DK, Magnussen H: Factor analysis of exercise capacity, dyspnoea ratings and lung function in patients with severe COPD. Eur Respir J 1994, 7:725-729.
Publish with Bio Med Central and every scientist can read your work free of charge

"BioMed Central will be the most significant development for disseminating the results of biomedical research in our lifetime. "

Sir Paul Nurse, Cancer Research UK

Your research papers will be:

- available free of charge to the entire biomedical community

- peer reviewed and published immediately upon acceptance

- cited in PubMed and archived on PubMed Central

- yours - you keep the copyright

Submit your manuscript here:

http://www.biomedcentral.com/info/publishing_adv.asp 